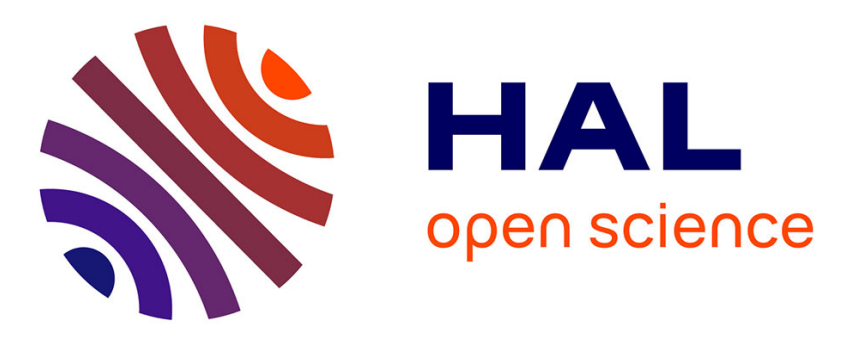

\title{
Impact of prior interventional treatment on the complications after Frey procedure for chronic pancreatitis
}

\author{
A Merdrignac, D Bergeat, F Robin, E Gaignard, K Turner, M Rayar, B. \\ Meunier, K Boudjema, Laurent Sulpice
}

\section{To cite this version:}

A Merdrignac, D Bergeat, F Robin, E Gaignard, K Turner, et al.. Impact of prior interventional treatment on the complications after Frey procedure for chronic pancreatitis. Langenbeck's Archives of Surgery, 2019, 404 (7), pp.825-830. 10.1007/s00423-019-01832-8 . hal-02363648

\section{HAL Id: hal-02363648 \\ https://hal-univ-rennes1.archives-ouvertes.fr/hal-02363648}

Submitted on 11 Dec 2019

HAL is a multi-disciplinary open access archive for the deposit and dissemination of scientific research documents, whether they are published or not. The documents may come from teaching and research institutions in France or abroad, or from public or private research centers.
L'archive ouverte pluridisciplinaire HAL, est destinée au dépôt et à la diffusion de documents scientifiques de niveau recherche, publiés ou non, émanant des établissements d'enseignement et de recherche français ou étrangers, des laboratoires publics ou privés. 
Impact of prior interventional treatment on the complications after Frey procedure for chronic pancreatitis

A. Merdrignac ${ }^{1}$, D. Bergeat ${ }^{1}$, F. Robin ${ }^{1}$, E. Gaignard ${ }^{1}$, K. Turner $^{1}$, M. Rayar ${ }^{1,2}$, B. Meunier ${ }^{1}$, K. Boudjema ${ }^{1,2}$, L. Sulpice ${ }^{1,2}$

${ }^{1}$ Université de Rennes 1, CHU Rennes, Service de Chirurgie Hépatobiliaire et Digestive, INSERM 1241, NuMeCan (Nutrition Metabolism and Cancer), 2 rue Henri Le Guilloux, F35000 Rennes, France

${ }^{2}$ Université de Rennes 1, INSERM 1414, CIC, 2 rue Henri Le Guilloux, F-35000 Rennes, France

\section{Corresponding author :}

Pr Laurent Sulpice

Service de chirurgie hépatobiliaire et digestive

2 rue Henri le Guilloux

35000 Rennes

Tel : +33 299284265

laurent.sulpice@chu-rennes.fr

\section{Original article}

The study has been presented at the $13^{\text {th }}$ French congress of digestive and hepato-biliopancreatic surgery.

Funding: the study did not receive financial support. 


\section{Abstract}

Purpose: Chronic pancreatitis is an inflammatory disease responsible for pain partially explained by pancreatic duct dilatation. Early surgery has become the treatment of choice for hypertrophic pancreatic head with main pancreatic duct dilatation. Frey procedure (FP), combining both surgical resection and decompression, is one of the standard surgical procedures. However, a "step-up approach" with endoscopic or limited surgical procedures is still frequently proposed before referring to expert pancreatic centers. The aim of the study was to evaluate the impact of a prior treatment on postoperative complications of FP.

Methods: All 61 consecutive patients who underwent FP between 2006 and 2017 were included. Perioperative data and outcomes were analyzed and compared according to the presence of a prior treatment.

Results: Twenty-four patients did not receive any prior treatment and thirty-seven patients had a prior endoscopic or limited surgical treatment. Preoperative data and outcomes were similar between the 2 groups. The rate of biliary derivation during FP was significantly higher in the group without prior endoscopic procedure. A prior treatment was not a risk factor for major morbidity (Clavien grade $\geq I I I)$.

Conclusions: A first attempt of endoscopic or limited surgical procedures before FP may not influence postoperative complications. Even if not recommended, a "step-up approach" proposing a first less invasive treatment could still be proposed to the patients who want to delay a morbid surgical procedure.

Keywords: chronic pancreatitis, pancreatic surgery, Frey procedure

Authors contributions: Study conception: AM and LS. Acquisition of data: AM, FR, EG and KT. Analysis and interpretation of data: AM, DB and MR. Drafting of manuscript: AM and LS. Critical revision of manuscript: AM, BM, KB and LS. 


\section{Introduction}

Chronic pancreatitis $(\mathrm{CP})$ is characterized by pancreatic parenchymal lesions progressing from inflammation to fibrosis and calcifications. Pain is the main resulting symptom and its management is a therapeutic challenge [1]. Although the origin of pain is not clearly known and certainly multifactorial, an enlargement of main pancreatic duct due to obstruction by strictures or stones is generally observed. The aim of both endoscopic and surgical procedures is to decrease pressure in the main pancreatic duct. Endoscopic treatment involves sphincterotomy, dilatation of strictures by temporary stent, removal of stones and extracorporeal shock wave lithotripsy. Complications of endoscopic treatment are post endoscopic retrograde cholangiopancreatography (ERCP) pancreatitis (3.5\%), infection (1.4\%), hemorrhage (1.3\%) and perforation (0.6\%) [2]. Post ERCP complications lead to a death rate of less than $1 \%$ mostly due to severe pancreatitis.

Surgical techniques consist in drainage of main pancreatic duct, resection or association of both. In cases of hypertrophic pancreatic head, surgical treatment mostly consists in hybrid procedures associating main pancreatic duct decompression and duodenum-preserving pancreatic head resection such as the Frey procedure (FP). Several previously published studies have demonstrated that FP offers an effective pain relief and is a safe surgical technique in the management of CP [3]. Frey procedure is associated with $25 \%$ rate of postoperative morbidity and less than $1 \%$ rate of mortality $[3,4]$. The most frequent specific complication after FP are postoperative bleeding (10-20\%) and pancreatic fistula (8-10\%) [3, 5].

For patients with obstructive $\mathrm{CP}$ and dilated pancreatic duct, surgery is superior to endoscopy in terms of pain relief $[6,7]$. In a Cochrane review, morbidity and mortality seem not to differ between the two intervention modalities, but the power of the trials was not sufficient to detect the small differences expected in this outcome [6]. Surgical intervention at an early stage of $\mathrm{CP}$ is a promising approach in terms of pain relief and pancreatic function. Early surgery has become the strategy of choice for expert pancreatic centers [8-10]. A 
randomized controlled trial has been conducted to compare early surgery vs endoscopy but results have not been published yet (ESCAPE trial ISRCTN45877994) [10]. The development of central pain (sensitization) is a concern when surgical intervention is delayed [11]. A delayed surgical intervention will not be beneficial in terms of pain-relief. Negi et al. conclude that patients should be referred for surgery before opiates are needed to relieve pain [12]. These results are confirmed by Ahmed Ali et al. who recommend surgery within 3 years of symptomatic CP [13]. In patients with an enlarged pancreatic head, a recent international survey of pancreatologists has shown that $58 \%$ preferred initial surgery (pylorus preserving pancreaticoduodenectomy) versus 42\% initial endoscopy [14].

However, currently, some patients are still referred to expert pancreatic centers after a first "step up approach". The impact of a prior endoscopic treatment on postoperative complications is not studied and known. Moreover, some patients do not present initial cephalic pancreatic complications of chronic pancreatitis and require first distal, decompressive or urgent pancreatic surgical procedures. The aim of the study was to evaluate the impact of a prior endoscopic or surgical treatment on the postoperative complications of Frey procedure for painful CP with hypertrophic pancreatic head. 


\section{Patients and methods}

\section{Patients}

A database of all consecutive patients who underwent the FP in a tertiary centre has been created and maintained prospectively since 2006 after institutional approval and informed consent. Data were collected regarding demographics, preoperative procedures (endoscopic, surgical, radiologic), surgical variables, length of hospital stay, postoperative morbidity, and follow-up. All patients operated between 2006 and 2017 were included in the analyses. No patient was excluded of the analysis. Diagnosis of CP was based on the clinical (clinical history, physical examination) and imaging findings (computed tomographic scan, magnetic resonance cholangiopancreatography, endoscopic ultrasound). Indication for surgery was systematically determined during a multidisciplinary meeting including surgeons, gastroenterologists and radiologists. Patients were divided into two groups according to the presence of a prior endoscopic procedure (attempts of pancreatic and/or biliary catheterism) or pancreatic surgery for $\mathrm{CP}$.

\section{Surgical procedure}

FP was performed by one senior pancreatic surgeon (LS) according to the technique first described in 1987 by Frey [15]. The need for biliary diversion was determined preoperatively or perioperatively when common bile duct (CBD) stricture persisted as observed by perioperative cholangiography. The type of biliary diversion chosen in case of CBD stricture depended on the accessibility of the CBD in the resection cavity and was left to the discretion of the surgeon.

The technique of $\mathrm{CBD}$ reinsertion combined a 1-cm longitudinal cut of the distal $\mathrm{CBD}$ in the pancreatic head resection cavity and an anastomosis to pancreatic parenchyma using 5-0 polydioxanone interrupted sutures. A Roux-en-Y choledochojejunostomy was performed if bilioenteric anastomosis was chosen. The same Roux-en-Y jejunal loop was used for the bilioenteric anastomosis and the pancreaticojejunal anastomosis. The distal extremity of the jejunal loop was first anastomosed with the pancreas. 


\section{Definitions}

The postoperative morbidity was defined as any complication that occurred within 90 days after surgery. The complications were categorized according to the Dindo and Clavien classification [16]. Major complications were categorized as grades III to $\mathrm{V}$ in the Dindo and Clavien classification. Postoperative pancreatic fistula was classified into three groups according to the criteria given by the International Study Group of Pancreatic Fistula [17]. Postoperative delayed gastric emptying was classified according to the criteria given by the International Study Group of Pancreatic Surgery (ISGPS) but only grade B and C were used for this study as our centre policy was to maintain the nasogastric tube until at least postoperative day 5 [18]. Postpancreatectomy haemorrhage including intra- and extraluminal bleeding was classified according to the ISGPS definition [19]. Biliary fistula was defined as the appearance of bile in peritoneal drains. Postoperative pain was defined as controlled if no analgesic was necessary or only level 1 analgesic according to the World Health Organization pain ladder (neither opioid nor weak opioid).

Statistical analysis

Qualitative variables are expressed as numbers with percentages and were compared using Fisher exact test. Quantitative variables are expressed as mean values \pm the standard deviation (SD) and were compared using Mann-Whitney $U$ test. p-values less than 0.05 were considered statistically significant. Analyses were performed with R statistical software (available: http://www.r-project.org/). 


\section{Results}

Sixty-one patients were operated for a FP between 2006 and 2017. Patients were divided in two groups: 37 patients with a prior endoscopic or pancreatic surgical procedure $(60.7 \%)$ and 24 patients without prior interventional treatment for CP (39.3\%). Nine patients underwent a prior pancreatic surgery: 3 cystogastric anastomosis, 3 distal pancreatectomies, 2 pancreaticojejunostomies, and 1 pancreatic necrosectomy. Twenty eight patients have had one or more prior endoscopic procedure: 5 pancreatic stenting, 2 biliary stenting, 3 cystogastric drainages and 21 attempts for endoscopic pancreatic drainage. The distribution of patients is presented in figure 1. Preoperative data were comparable between the two groups (table 1). The majority were male with CP due to alcohol abuse.

Postoperative data are presented in table 2. Operation time and hospitalization duration were similar. The rate of biliary derivation was significantly higher in the group without prior endoscopic procedure. The rate of major complication (Clavien $\geq I I I)$ was not different including pancreatic fistula and hemorrhage.

Mean follow-up was $24.6 \pm 21.4$ and $33 \pm 30.3$ months in the group with and without prior endoscopic or surgical procedure respectively $(p=0.3)$. Data on pain control at 2 years were available for 43 patients: 24 and 19 patients in the group with and without prior procedure respectively. Pain control was obtained for $95.8 \%$ and $84.2 \%$ patients $(p=0.3)$ in the group with and without prior procedure respectively. Data on diabetes mellitus at 2 years were available for 46 patients: 30 and 16 patients in the group with and without prior procedure respectively. Diabetes mellitus was present in $46.6 \%$ and $50 \%(p=1)$ in the group with and without prior procedure respectively.

Univariate analysis for identification of risk factors for complications with Clavien grade $\geq$ III is presented in table 3. Multivariate analysis was not realized because no risk factor was identified in univariate analysis. 


\section{Discussion}

The treatment of painful CP with hypertrophic pancreatic head could involve both endoscopic and surgical procedures. However, current recommendations indicate that the timing of surgical intervention is an important factor in clinical outcomes.

The "step-up approach" consists with a less invasive endoscopic treatment as first line therapy followed by surgical procedure in case of failure. Prolonged and repeated pancreatic stenting has been identified as a risk factor for failure after subsequent rescue surgery [13]. Moreover, the Dutch pancreatitis Study Group has argued against the "step-up approach" on the basis that opioids, the mainstay of conservative treatment, do not alter disease progression and that reliance on them delays intervention [20].

Nevertheless, a first less invasive approach using endoscopic procedure is still frequently proposed to patients before referring to expert pancreatic centers or if patients refused surgery. The present study shows similar rate of postoperative complications after FP between the patients who had a prior endoscopic or surgical treatment and those who were free of prior interventional treatment. One can hypothesize that specific complications of endoscopic procedures could influence surgical outcomes. Post-ERCP pancreatitis leads to local inflammation that could increase morbidity of pancreatic surgery. Chronic pancreatitis may be a protector factor for post-ERCP pancreatitis [21]. Conversely, difficult or failed cannulation is a risk factor for post-ERCP pancreatitis. The majority of patients with a prior endoscopic procedure in this study underwent a failure of pancreatic drainage. The similar rates of surgical morbidity in the 2 groups of this study are in accordance with the protecting effect of CP on post-ERCP pancreatitis. Moreover, a prior endoscopic or surgical treatment is not a risk factor for complications with Clavien grade $\geq \mathrm{III}$ in the present cohort.

In the group of patients with a prior endoscopic or surgical procedure, the need for a biliary diversion during FP was significantly lower. Among these patients, two had a biliary stenting that could have avoided the need for a biliary derivation during surgery and explain the statistical difference between the 2 groups. 
The main limits of the present study are the small number of patients and the long study period in a monocentric cohort. However, the majority of published cohorts do not exceed fifty patients. Pancreatic surgery is more frequently indicated for pancreatic neoplasms than for $\mathrm{CP}$ in Western Europe. This fact explains the difficulty to identify risk factors for complications after FP. Follow up of patients with CP is often difficult and leads to biases due to missing data.

\section{Conclusions}

The management of painful CP with enlarged pancreatic head involves both endoscopic and surgical procedures after failure of medical treatment. Several studies have shown benefit for early surgery on pain relief. The present study shows that a first attempt of endoscopic procedure before surgery may not influence postoperative complications. A preoperative biliary stenting could avoid the need for a surgical biliary derivation combined to the FP. A "step-up approach" could not be recommended but, in cases of patients referred after prior interventional treatment, patients could underwent Frey procedure without excess risk of postoperative complications.

\section{Compliance with Ethical Standards:}

Disclosure of potential conflicts of interest: The authors declare that they have no conflict of interest.

Research involving Human Participants: All procedures performed in the study involving human participants were in accordance with the ethical standards of the institutional research committee and with the 1964 Helsinki declaration and its later amendments or comparable ethical standards.

Informed consent: Informed consent was obtained from all individual participants included in the study 


\section{References}

1. Braganza JM, Lee SH, McCloy RF, McMahon MJ (2011) Chronic pancreatitis. The Lancet 377:1184-1197. https://doi.org/10.1016/S0140-6736(10)61852-1

2. Andriulli A, Loperfido S, Napolitano G, et al (2007) Incidence Rates of Post-ERCP Complications: A Systematic Survey of Prospective Studies. Am J Gastroenterol 102:1781. https://doi.org/10.1111/j.1572-0241.2007.01279.x

3. Zhou Y, Shi B, Wu L, et al (2015) Frey procedure for chronic pancreatitis: Evidencebased assessment of short- and long-term results in comparison to pancreatoduodenectomy and Beger procedure: A meta-analysis. Pancreatology 15:372-379. https://doi.org/10.1016/j.pan.2015.05.466

4. Suzumura K, Hatano E, Okada T, et al (2018) Short- and long-term outcomes of the Frey procedure for chronic pancreatitis: a single-center experience and summary of outcomes in Japan. Surg Today 48:58-65. https://doi.org/10.1007/s00595-017-1548-0

5. Ahmed Ali U, Pahlplatz JM, Nealon WH, et al (2015) Endoscopic or surgical intervention for painful obstructive chronic pancreatitis. In: Cochrane Database of Systematic Reviews. John Wiley \& Sons, Ltd

6. Strobel O, Büchler MW, Werner J (2009) Surgical therapy of chronic pancreatitis: Indications, techniques and results. Int J Surg 7:305-312. https://doi.org/10.1016/j.ijsu.2009.05.011

7. Yang CJ, Bliss LA, Schapira EF, et al (2014) Systematic Review of Early Surgery for Chronic Pancreatitis: Impact on Pain, Pancreatic Function, and Re-intervention. J Gastrointest Surg 1-7. https://doi.org/10.1007/s11605-014-2571-8

8. Yang CJ, Bliss LA, Freedman SD, et al (2015) Surgery for Chronic Pancreatitis: The Role of Early Surgery in Pain Management. Pancreas 44:819-823.

https://doi.org/10.1097/MPA.0000000000000333

9. Ke N, Jia D, Huang W, et al (2018) Earlier surgery improves outcomes from painful chronic pancreatitis. Medicine (Baltimore) 97:.

https://doi.org/10.1097/MD.0000000000010651

10. Ahmed Ali U, Issa Y, Bruno MJ, et al (2013) Early surgery versus optimal current stepup practice for chronic pancreatitis (ESCAPE): design and rationale of a randomized trial. BMC Gastroenterol 13:49. https://doi.org/10.1186/1471-230X-13-49

11. Anderson MA, Akshintala V, Albers KM, et al (2016) Mechanism, Assessment and Management of Pain in Chronic Pancreatitis: Recommendations of a Multidisciplinary Study Group. Pancreatol Off J Int Assoc Pancreatol IAP Al 16:83-94. https://doi.org/10.1016/j.pan.2015.10.015

12. Negi S, Singh A, Chaudhary A (2010) Pain relief after Frey's procedure for chronic pancreatitis. Br J Surg 97:1087-1095. https://doi.org/10.1002/bjs.7042

13. Ali UA, Nieuwenhuijs VB, Eijck CH van, et al (2012) Clinical Outcome in Relation to Timing of Surgery in Chronic Pancreatitis: A Nomogram to Predict Pain Relief. Arch Surg 147:925-932. https://doi.org/10.1001/archsurg.2012.1094 
14. Issa $Y$, van Santvoort HC, Fockens $P$, et al (2017) Diagnosis and treatment in chronic pancreatitis: an international survey and case vignette study. HPB 19:978-985. https://doi.org/10.1016/j.hpb.2017.07.006

15. Frey CF, Smith GJ (1987) Description and rationale of a new operation for chronic pancreatitis. Pancreas 2:701-707

16. Dindo D, Demartines N, Clavien P-A (2004) Classification of surgical complications: a new proposal with evaluation in a cohort of 6336 patients and results of a survey. Ann Surg 240:205-213

17. Bassi C, Dervenis C, Butturini G, et al (2005) Postoperative pancreatic fistula: an international study group (ISGPF) definition. Surgery 138:8-13.

https://doi.org/10.1016/j.surg.2005.05.001

18. Wente MN, Bassi C, Dervenis C, et al (2007) Delayed gastric emptying (DGE) after pancreatic surgery: a suggested definition by the International Study Group of Pancreatic Surgery (ISGPS). Surgery 142:761-768.

https://doi.org/10.1016/j.surg.2007.05.005

19. Wente MN, Veit JA, Bassi C, et al (2007) Postpancreatectomy hemorrhage (PPH): an International Study Group of Pancreatic Surgery (ISGPS) definition. Surgery 142:20-25. https://doi.org/10.1016/j.surg.2007.02.001

20. Issa Y, Santvoort HC van, Goor H van, et al (2013) Surgical and Endoscopic Treatment of Pain in Chronic Pancreatitis: A Multidisciplinary Update. Dig Surg 30:35-50. https://doi.org/10.1159/000350153

21. Freeman ML (2007) Pancreatic Stents for Prevention of Post-Endoscopic Retrograde Cholangiopancreatography Pancreatitis. Clin Gastroenterol Hepatol 5:1354-1365. https://doi.org/10.1016/j.cgh.2007.09.007

\section{Legends}

Table 1: Preoperative data of all patients divided in two groups according to the presence of a prior endoscopic or surgical procedure for chronic pancreatitis.

Table 2: Postoperative data of all patients divided in two groups according to the presence of a prior endoscopic or surgical procedure for chronic pancreatitis.

Table 3: Univariate analysis for identification of risk factors for complications with Clavien grade $\geq$ III

Figure 1: Distribution of all patients according to prior treatment for chronic pancreatitis. 


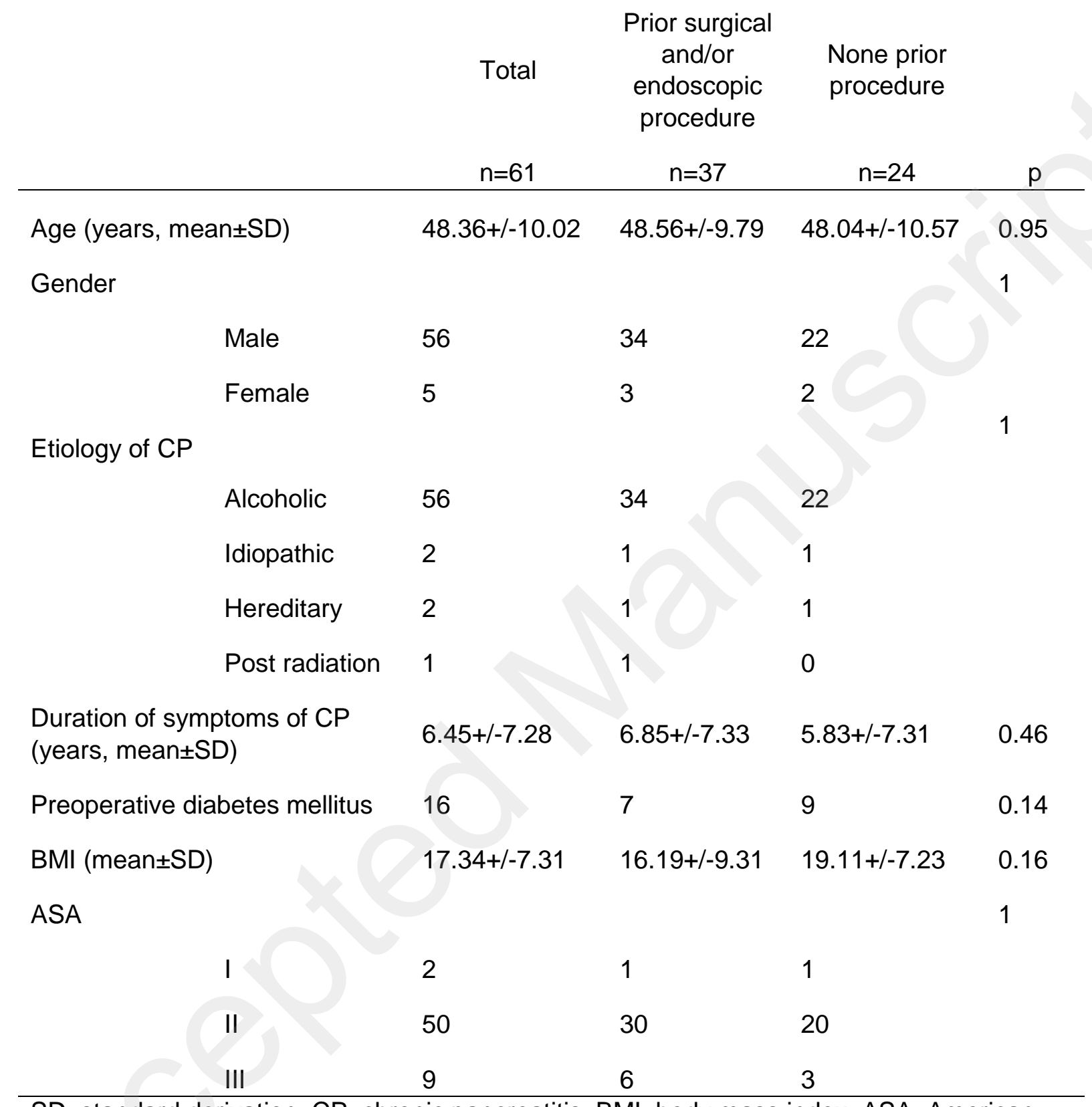

SD: standard derivation, CP: chronic pancreatitis, BMI: body mass index, ASA: American society of anesthesiologists

Table 1: Preoperative data of all patients divided in two groups according to the presence of a prior endoscopic or surgical procedure for chronic pancreatitis (CP). 


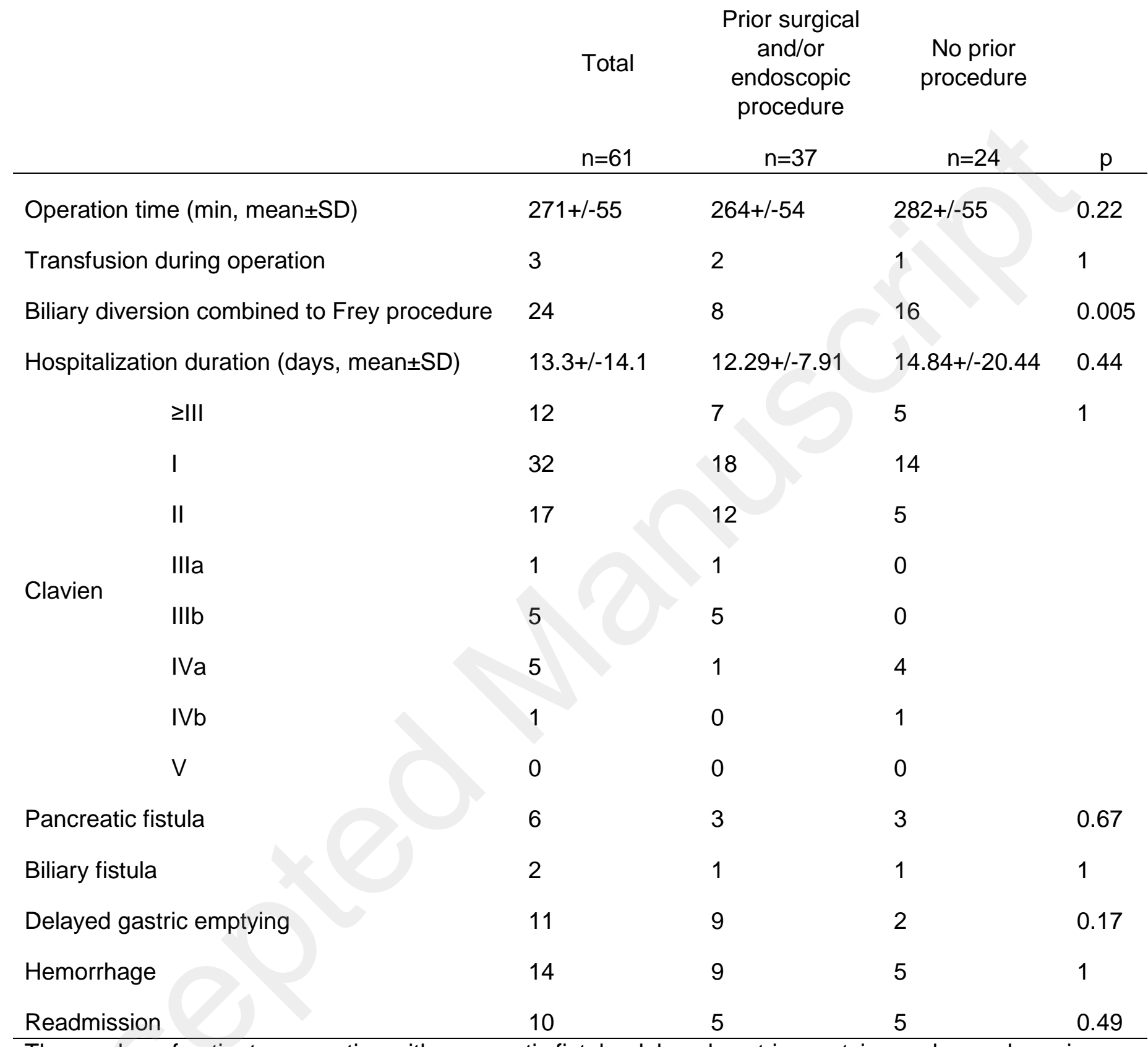

The number of patients presenting with pancreatic fistula, delayed gastric emptying, or hemorrhage is equal to the sum of all grades to permit statistical analyses. SD: standard derivation.

Table 2: Postoperative data of all patients divided in two groups according to the presence of a prior endoscopic or surgical procedure for chronic pancreatitis. 


\begin{tabular}{|c|c|c|c|c|}
\hline & $\begin{array}{l}\text { Total } \\
\mathrm{n}=61\end{array}$ & $\begin{array}{c}\text { Clavien } \\
\text { grade<III } \\
n=49\end{array}$ & $\begin{array}{c}\text { Clavien } \\
\text { grade } \geq \text { III } \\
n=12\end{array}$ & $p$ \\
\hline Gender & & & & 0.5726 \\
\hline Male & 56 & 44 & 12 & \\
\hline Female & 5 & 5 & 0 & \\
\hline Age (years, mean $\pm S D$ ) & $48.36+/-10.02$ & $48.06+/-10.17$ & $49.58+/-9.71$ & 0.6048 \\
\hline BMI (mean $\pm S D)$ & $20.99+/-2.91$ & $20.78+/-2.9$ & $21.84+/-2.92$ & 0.3183 \\
\hline $\begin{array}{l}\text { Duration of symptoms (years, } \\
\text { mean } \pm S D \text { ) }\end{array}$ & $5.93+/-6.27$ & $6.17+/-6.61$ & $4.96+/-4.72$ & 0.5775 \\
\hline Preoperative diabetes mellitus & 16 & 14 & 2 & 0.4899 \\
\hline ASA & & & & 0.5947 \\
\hline 1 & 2 & 2 & 0 & \\
\hline II & 50 & 41 & 9 & \\
\hline III & 9 & 6 & 3 & \\
\hline $\begin{array}{l}\text { Prior endoscopic or surgical } \\
\text { procedure }\end{array}$ & 37 & 30 & 7 & 1 \\
\hline Biliary derivation & 24 & 20 & 4 & 0.73 \\
\hline Enucleation diameter $(\mathrm{cm}$, mean $\pm S D)$ & $4.12+/-1.15$ & $4.18+/-1.21$ & $3.87+/-0.83$ & 0.4988 \\
\hline Enucleation volume $\left(\mathrm{cm}^{3,}\right.$ mean $\left.\pm S D\right)$ & $26.48+/-18.98$ & $27.25+/-19.99$ & $23.44+/-14.54$ & 0.7393 \\
\hline
\end{tabular}

SD: standard derivation

Table 3: Univariate analysis for identification of risk factors for complications with Clavien grade $\geq$ III 


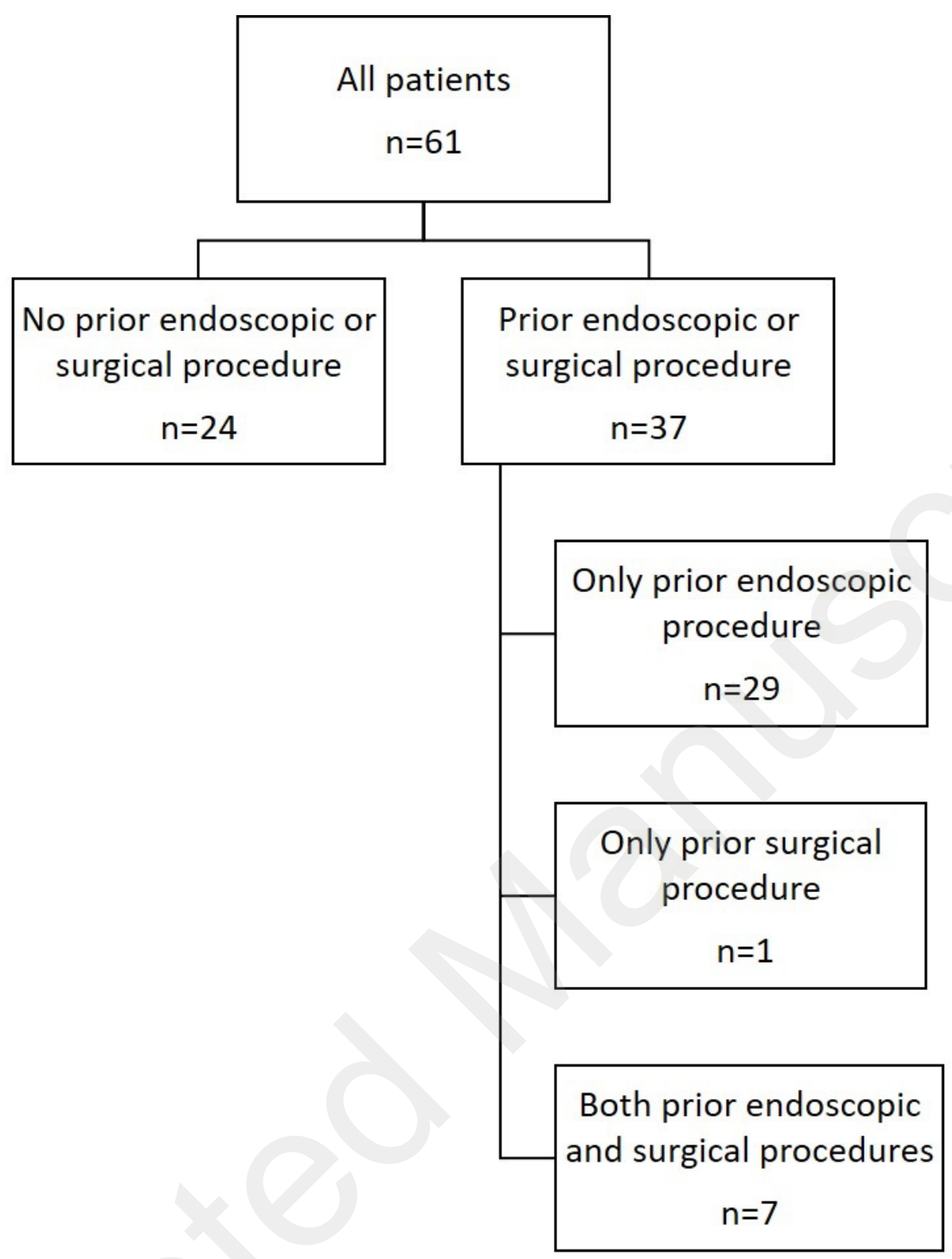

Figure 1: Distribution of all patients according to prior treatment for chronic pancreatitis. 